\title{
Research of Safety Assessment of Work System in Construction
}

\author{
Project \\ XianMing Xie * \\ State Grid Hubei Electric Power Company, China \\ *Corresponding author: XianMing Xie, Master, 1759415840@qq.com
}

\begin{abstract}
The accidents data are used as factor dominance relation in Analytic Network Process. Then, aiming to the bent puts up operation, with the inspection process monitoring data as input, it gives assessment results through the variable assignment and the factors weight derived from ANP method. After a period of monitoring and rectification, it implements a new round of safety monitoring and factors comparison and interaction analysis, so to achieve the goal of "the nature of safety" of hydropower projects construction.
\end{abstract}

Keywords: safety assessment; high-risk work system; behavior factor; accidents data analysis; ANP;

\section{Introduction}

We select total 32 safety accidents related to work system in the construction projects, which caused 35 deaths and 4 severe injuries. Based on the identification of the hazardous sources, it is of great necessity to carry out safety assessment of work system in construction projects, to provide a guideline of safety monitoring based on safety assessment, to strengthen management of potential accidents and to prevent and control accidents ${ }^{1,2}$. Therefore, it is necessary to analyze the factors which can cause the accidents in construction projects, the methods to assess the safety levels of work system in construction projects, and the applications of those methods.

\section{Research methodology}

The safety assessment in high-risk work system should firstly analyse safety risk factors based upon the identification of risk factors, then we construct the risk assessment structure model by the classification of factors and hierarchical structure ${ }^{3,4}$. The calculation process is quantitative evaluation combined with expertise and accident statistics. The research methodology is as follows:

Amending HFACS framework factors and combining with case data of accidents and expertise, finally we determine the risk factors. The risk factors after adjustment are described diagrammatically in Figure 1. 


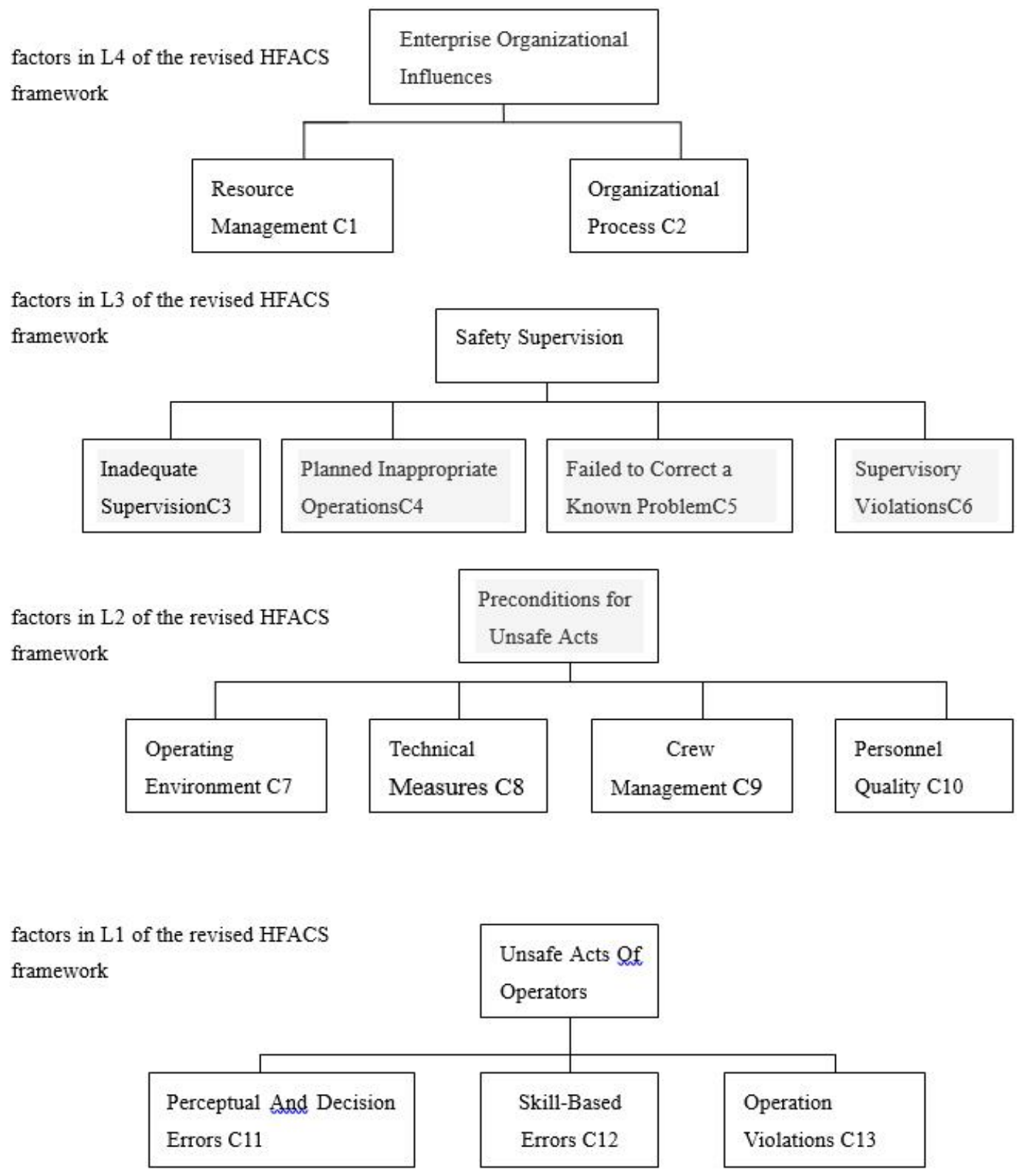

Fig. 1 The basic framework of four-layer for risk factors of high-risk operations

We use chi-square test for association analysis to identify the relation between factors. With the comparative data between the factors, build ANP super-matrix, weighted super-matrix and ultimate super-matrix, calculate the local weight and global weight of factors ${ }^{5}$. Describe the value-at-risk by the use of fuzzy language variable, and then build risk vector of factors. Aimed at Specific high-risk jobs, with standardized forms and security check, we can master the security risk value of High-risk jobs, which is mainly on site and inside the industry ${ }^{6}$. Use decision support software tools such as Super Decisions to calculate the risk value of high-risk operations ${ }^{7}$.

\section{3 models and computational analysis}

According to the risk factors framework of figure 1, we can firstly analysis the 
relationship of factors, which affect each other. According to the data of accident case, we count the risk factors of every accident. Statistical process is followed to determine the factors in accident cases the accident given by the corresponding HFACS factors. We should calculate the ratio of the value of each category of factors to analyze the impact of the accident, identify the factors relatively large proportion of species.

According to HFACS framework and the interaction between behavioral factors, we can construct ANP network hierarchy structure of evaluation model. It shows in Figure 2. The model reflects the relation between the factors in the criteria layer.

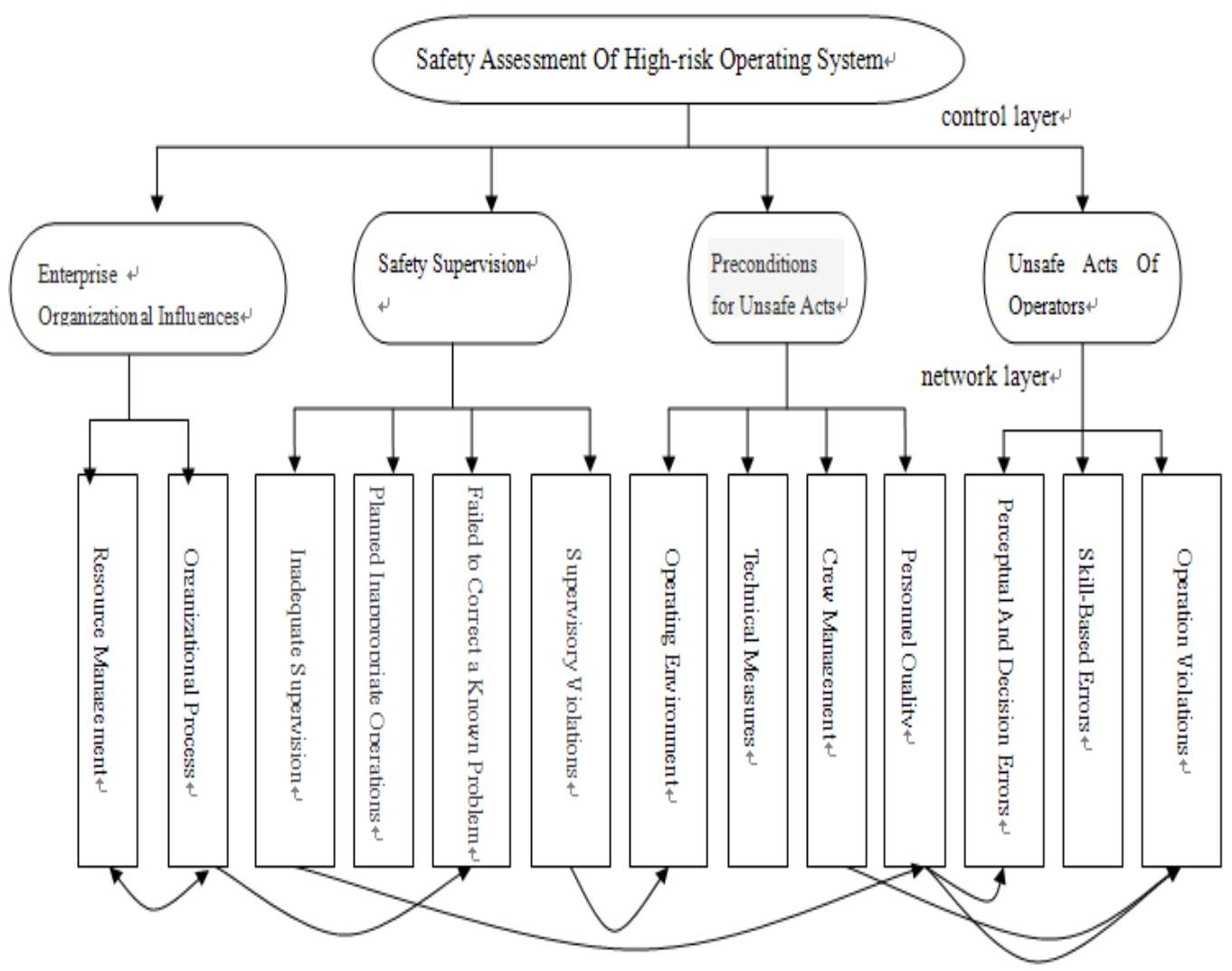

Fig. 2 Delivery-level hierarchy and the relationship between the factors of ANP

ANP solution process combined with statistical methods is a purely quantitative calculation, rather than semi-qualitative and semi-quantitative process depending on experts.

According to Figure 2, draw ANP network hierarchy model in SD interface with SD software, which reflects the relation between factors in the criteria layer. In the network layer, we have four categories in an element set, they are enterprise organizational influences, safety supervision, precondition for unsafe acts and unsafe acts of operators, each category has different number of elements, respectively, there are 13 evaluation indicators (behavioural factors) in total. As the four evaluation criteria involved in high-risk operation evaluation are not independent of each other, 
you can see the circular arrows. In the same way, the 13 indicators (behavioral factors) involved in the four evaluation criteria are not independent of each other as well, circular arrows exist, too. The relationships between them have been discussed previously, here can the conclusion be used directly.

\section{Case study}

According to the weights of behavioral factors given above, it is able to calculate the risk value of high-risk operations system combined with factors value of risk assessment variable (value of assessment variable for short). Therefore, it needs to study to determine the value of assessment variable about the behavioral factors. Since high-risk operation involves many types, such as the specific risk factors of high-bent erection are quite different from the ones of installation of large equipment, it is of little value to guide practice by continuing to use behavior factors in macro-level to analyze the risk of high-risk operations. The following is about specific high-risk operations, it is a study of specific factors and the corresponding behavioral factors in macro-level , through process monitoring of high-risk operations, the value of assessment variable of specific risk factors and behavioral factors in macro-level can be determined, and combined with the safety evaluation results of high-risk operations, the process monitoring can be guided..

The rules about the value of risk assessment variable are as follows: for each inspection item, results of inspection can be divided into four categories according to the degree, such as "matched", “just matched", “unmatched generally", "unmatched seriously", their values of risk assessment variable are 0, 0.25, 0.5, 0.75 orderly. If there is a number of inspection items which belong to the same behavioral factor, determining the value of assessment variable of behavioural factors should firstly base on the principle of high risk in front. Secondly, if there are many inspection items unmatched, the corresponding value of assessment variable of behavioral factors adds 0.2 repeatedly for each generally unmatched one. If the total comes to one, or two more inspection items are unmatched seriously, then FBR of high-risk operating system values one prescriptively, and it does not continue to be calculated.

In accordance with risk value FBR, follow-up measures can be decided:

(1) If FBR $>=0.4$, stop work and rectify, redesign and reorganize, until the new risk assessment meets the requirements.

(2) If $0.4>F B R>=0.2$, rectify, and re-evaluation after the rectification.

(3) If $\mathrm{FBR}<0.2$, the high-risk operating system is safe.

The inspection about the process of gantry crane installation and assessment results are described in Table 1. 
Table 1 The assessment value of gantry crane installation

\begin{tabular}{|c|c|c|c|c|}
\hline \multirow[b]{2}{*}{ Behavioral factors } & \multirow{2}{*}{$\begin{array}{l}\text { ANP } \\
\text { weights }\end{array}$} & \multicolumn{3}{|l|}{ Gantry crane installation } \\
\hline & & Inspection results & $\begin{array}{l}\text { Value of } \\
\text { assessment } \\
\text { variable }\end{array}$ & Product \\
\hline ResourceManagement C1 & 0.0075 & none & 0 & 0 \\
\hline $\begin{array}{l}\text { OrganizationalProcess } \\
\text { C2 }\end{array}$ & 0.0131 & matched & 0 & 0 \\
\hline InadequateSupervisionC3 & 0.099 & matched & 0 & 0 \\
\hline $\begin{array}{l}\text { Planned Inappropriate } \\
\text { Operations C4 }\end{array}$ & 0.0168 & matched & 0 & 0 \\
\hline $\begin{array}{l}\text { Failed to Correct a } \\
\text { Known Problem C5 }\end{array}$ & 0.0393 & matched & 0 & 0 \\
\hline SupervisoryViolations C6 & 0.0393 & matched & 0 & 0 \\
\hline OperatingEnvironmentC7 & 0.1235 & $\begin{array}{l}3 \text { items of unmatched } \\
\text { generally }\end{array}$ & 0.9 & 0.1112 \\
\hline Technical Measures C8 & 0.0692 & matched & 0 & 0 \\
\hline Crew Management C9 & 0.0374 & matched & 0 & 0 \\
\hline Personnel Quality C10 & 0.1906 & none & 0 & 0 \\
\hline $\begin{array}{l}\text { Perceptual And Decision } \\
\text { Errors C11 }\end{array}$ & 0.1518 & none & 0 & 0 \\
\hline Skill-Based Errors C12 & 0.0131 & none & 0 & 0 \\
\hline Operation Violations C13 & 0.1995 & $\begin{array}{l}\text { 1item of unmatched } \\
\text { generally }\end{array}$ & 0.5 & 0.0998 \\
\hline
\end{tabular}

Sum the risk value of all the factors in Table 1, and know the risk value FBR about the process of gantry crane installation is 0.211 , so general rectification is suitable.

\section{Conclusions and prospects}

Current safety evaluation methods generally use the subjective qualitative or semi-qualitative principle, so they cannot evaluate the current security management and size of risk about the high-risk operations quantificational. AHP as a quantitative assessment method can evaluate the risk without considering the correlations between factors. In response to this, ANP method has been modified. However, either of the two methods uses a simple way of experts' evaluation to determine judgment matrixes of the factors, thus qualitative properties remain and the accuracy of the evaluation depends heavily on the expertise. In this paper, by statistical methods, accident statistics is analysed, thereby the correlation between factors can be determined more precisely, based on this, with combination of the frequency of factors, the weights can be determined. Therefore, it is a more objective quantitative method. The use of process monitoring finds the unmatched items in the checklist, and then according to this, the corresponding behavioral factors can come out. With that, value of assessment variable about factors can be determined; finally, the evaluation results will be obtained. Because behavioral factors correspond with checking items, safety evaluation and process monitoring have a reasonable interface, and by using safety monitoring for the basis data sources of evaluation, safety-monitoring work can be guided in return. 


\section{References}

1. J. Zhou, J. Pei, The discussion of hydropower project construction safety standards for the terms of the preparation of tender documents (in Chinese), J. Yangtze River. 2008, 39(16): 94-97.

2. D.A.Wiegmann, S.A. Shappell, Human error analysis of commercial aviation accidents: application of the human factors analysis and classification system. Aviat. Space Env. Med., 2001a, 72: 1006-1016.

3. Q. Zhang, Hazard identification and risk assessment of the major safety construction (in Chinese), J. GUANGDONG Building Materials, 2008, 7, 266-268.

4. D. Peng, X. Zhen, Four Dangers Condition Identification and Control in Water and Electricity Project Construction Work System (in Chinese), J. Construction Technology, 2007,26(5): 70-72.

5. K.Wang, $X . X u$, G. Miao, FMECA Analysis of the Work Safety on Attached Self-lifting Scaffolds (in Chinese), J. CHINA SAFETY SCIENCE JOURNAL, 2008, 18(3): 138-142.

6. D. Peng, X. Zhen, Four Dangers Condition Identification and Control in Water and Electricity Project Construction Work System (in Chinese), J. Construction Technology, 2007,26(5): 70-72.

7. K.Wang, X. Xu, G. Miao, FMECA Analysis of the Work Safety on Attached Self-lifting Scaffolds (in Chinese), J. CHINA SAFETY SCIENCE JOURNAL, 2008, 18(3): 138-142. 